\title{
SMART MOBILE APPLICATION FOR DECISION SUPPORT SYSTEMS ON DETERMINATION OF RESIDENT IN DORMITORY
}

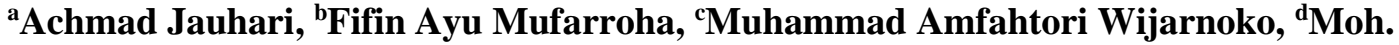 \\ Yusril Ihza Maulana, ${ }^{\mathrm{e} A h m a d}$ Try Bayu Al Haq, ${ }^{\mathrm{f}}$ Linawati \\ a,b,c,d,e,f Departement of Informatic Engineering, University of Trunojoyo Madura, Bangkalan - \\ Madura, Indonesia \\ E-mail: ajauhari@trunojoyo.ac.id, bfifin.mufarroha@trunojoyo.ac.id
}

\begin{abstract}
The dormitory is one of the facilities provided with the aim of helping students to get a place to live because some of them come from distant places. The Trunojoyo Madura University dormitory has regulations that serve as a place for the process of character education, spiritual deepening, moral improvement. With these regulations, plus the boarding house is a conducive, economical, and strategic place to stay making many students interested in being able to live there. The problem is that each semester change is carried out by the selection of dorm residents and so far it is still done manually by way of discussion of each individual. Therefore, the purpose of this research is to help the board by building a decision support system in determining residents who are still eligible to live in a dormitory and provide opportunities for other students to live in a dormitory. We develop systems based on mobile applications. TOPSIS method (Technique for Order of Preference by Similarity to Ideal Solution) is implemented as a multi criteria decision making method with four main criteria including routine absence, non-routine absence, violation and notes. The final results of this decision support system are ranks and colors that indicate the status of boarding residents. Ranking starts from the top (1) to the bottom (216) accompanied by a status of green to red. The color status is divided into 3 namely green (safe), yellow (vulnerable), and red (issued). From 216 boarders we took 10 samples of dormitory data for testing. The results of trials with 10 data samples by applying the TOPSIS method obtained an accuracy of $90 \%$.
\end{abstract}

Key words: mobile application, decision support system, dormitory, TOPSIS method. 


\section{INTRODUCTION}

Dormitory is a building located in an agency that serves as a residence for members or groups, generally school students. Dorms usually consist of rooms that can be occupied by several people at once. The period of stay in the dormitory is longer or longer than in hotels and inns. One of the reasons students choose to live in a dormitory is that it is still an area with a place to study and the costs are relatively cheap when compared to other lodging such as apartments.

Some universities have student dormitories in accordance with Presidential Decree No. 40 of 1981, as well as the University of Trunojoyo Madura. The Trunojoyo Madura University student dormitory has a dual function which is as a conducive, economical, and strategic residence because it is within the campus area, as well as a place for the process of character education, spiritual deepening, moral improvement, intellectual development and strengthening the interests of talents as well as students' social care as successors a trustworthy, religious, caring and creative nation. Every semester change, the dormitory selects the residence residents. Residents of the dormitory are designations for students who live in the dormitory. The selection that has been done so far is manual, that is, it only conducts discussions among the residents of the dormitory one by one. With the selection support system for residents living in a dormitory, it is very helpful for the dormitory to do the selection. The selection is done to see whether the dormitory residents are still eligible to live in a dormitory and provide opportunities for other students who want to live in a dormitory.

Decision Support System (DSS) is a system that can help in making decisions in an organization or company [1]. In addition, decision support systems can solve problems in complex environments both in terms of hardware and software [2]. In education the Decision Support System can be seen as an important asset to support the smoothness and accuracy in achieving a goal. One of them is to determine or select, by using a decision support system. The selection process for boarding residents will be more objective and targeted by implementing the solution. Many methods are used in decision support systems such as TOPSIS (Technique for Order
Preference by Similarity to Ideal Solution) [36], SAW(Simple Additive Weighting) [7, 8], AHP (Analytical Hierarchy Process) [9-11] and several studies using the combination [12]. The SAW method reveals the criteria value based on its weight. This method uses the usual multiplication and addition operations and the values of these methods must be numeric so they can be compared [13]. While the AHP method uses pairwise comparisons obtained from interconnected criteria. This comparison process aims to find the interconnected krteria weight [14]. One other method that is widely used is TOPSIS. TOPSIS is one of the multi-criteria decision making methods by applying weighting values to each criterion, this method uses the principle that the chosen alternative must have the shortest distance from the positive ideal solution and the farthest distance from the negative ideal solution [4]. The application of the TOPSIS method helps in the process of determining the selection method to be applied. The proposed method has correctly resolved problems in decision making with various criteria and groups [6]. This means that the choices will be sorted by the resulting value so that the alternative that has the shortest distance with a positive ideal solution is the best alternative. The purpose of this study is to help board administrators make the selection process in determining who are eligible to live in a dormitory..

\section{MATERIAL AND METHOD}

In system development, we build a mobile based system. The reason for choosing mobilebased is that many users are more comfortable using it and users can access it anywhere and anytime [15]. Smartpone is a modern communication tool that has been widely used by the public. The data used in this system is The student data feature contains a list of students who are residents in the dormitory. The data we get, the number of citizens currently living as many as 216 residents. the stages in system development can be seen in Figure 1.The process begins with collecting data on students who are residents of the dormitory. The processed data is the raw data in excel format obtained from the management of the dormitory. the next process, we designed the system by applying the TOPSIS method into the system. the application of the 
TOPSIS method is implemented as a method in the process of determining dormitory residents. After obtaining the design method, the next step is to build the system. We have used one of the software in android development, namely android studio and implemented firebase in database storage. in testing, we perform validation testing. Validation testing is done to determine the results of the manual calculation of TOPSIS and the results of the prediction system.

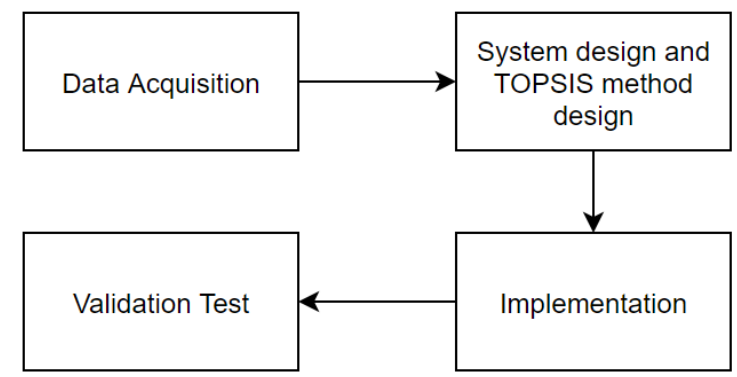

Fig 1. System development

\section{Decision Support System}

One area of scientific discipline in information systems is decision support systems. This system is focused on supporting and improving managerial decision making [16]. In the decision making process utilizing data and selecting certain models for the search for solutions that involve human intuition in making decisions. In various decision making situations, we need to differentiate computerized support for automated support systems and decision support systems. Automatic decision systems are intended to automate and make decisions in routine and well-structured situations while decision support systems are additional systems intended to help decision makers in various semi-structured and repetitive decision-making situations [17]. From the explanation above, we can conclude that the decision support system can be divided into several decision situations. The situation can be structured and unstructured.

\section{TOPSIS Method}

TOPSIS is a multi-criteria decision making method used to determine the best alternative in the solution concept. Euclidean distance is applied in finding the shortest distance in finding the best alternative solution or expressed as a positive ideal solution. The farthest distance from the solution will be expressed as a negative solution [5]. The positive ideal solution is defined as the sum of all the best values that can be achieved for each attribute, while the negative ideal solution consists of all the worst values achieved for each attribute. The following steps must be prepared before starting the TOPSIS calculation process.

1. Alternative data

Alternative data as a representation of a person / object to be assessed. Alternative data usually consists of alternative code and names, some attribute additions are tailored to the case being studied.

2. Criteria data

Criteria data are used as a basis for evaluating alternatives. Criteria can be in the form of costs or benefits. the greater the value of the benefits will mean good. and vice versa for the smaller the value the better.

3. Alternative Values

Assigning values to alternatives in each criterion data is referred to as alternative values. For ease of understanding is represented in the form of a table (matrix) with the alternative as the title line and criteria as the column headings. It should be noted that each alternative must have a value on all criteria even though it is zero.

4. Normalization

Calculate the normalized matrix with equation 1 :

$r_{i j}=\frac{x_{i j}}{\sqrt{\sum_{i=1}^{m} x_{i j}^{2}}}$

$r_{i j}=$ normalized value decision value matrix

$x_{i j}=$ initial value decision matrix

5. Weighted Normalization

$y_{i j}=\left[\begin{array}{ccc}W_{11 r_{11}}^{V_{1 i}=W_{i} r_{i j}} & \cdots & W_{1 n} r_{1 n} \\ \vdots & \ddots & \vdots \\ W_{m 1} r_{m 1} & \cdots & W_{m n} r_{n m}\end{array}\right]$

$y_{i j}=$ weighted normalized decision matrix

$w_{i}=$ criteria weights $i$ 
6. The Ideal Solution Matrix

Determine the ideal solution $A^{+}$and negative ideal solutions $A^{-}[18]$.

positive

$A^{+}=y_{1}^{+}, y_{2}^{+}, \cdots, y_{n}^{+}$

Negative

$A^{-}=y_{1}^{-}, y_{2}^{-}, \cdots, y_{n}^{-}$

$y_{1}^{+}=\max y_{i j}$, if $j$ is an attribute of excess (benefit)

$y_{1}^{-}=\min y_{i j}$, jika $j$ is an attribute of costs

7. Distance Positive Ideal / Negative Solution

Distance alternatives with positive solutions positively formulated [12]:

$$
D_{i}^{+}=\sqrt{\sum_{j=1}^{n}\left(y_{i j}-y_{j}^{+}\right)^{2}}
$$

Alternative distances with the ideal Negative solution are formulated:

$$
\begin{aligned}
& D_{i}^{-}=\sqrt{\sum_{j=1}^{n}\left(y_{i j}-y_{j}^{-}\right)^{2}} \\
& \begin{aligned}
y_{j}^{+} & =\text {positive ideal solution for - } \\
& j \text { attribute } \\
y_{j}^{-} & =\text {negative ideal solution for - } \\
& j \text { attribute } \\
y_{i j}= & \text { elements of a normalized decision } \\
& \text { matrix weighted } y
\end{aligned}
\end{aligned}
$$

8. Value Preference

$$
V_{i}=\frac{D_{i}^{-}}{D_{i}^{-}+D_{i}^{+}}
$$

Defining Problems and Determining Solutions
a. Problem: Decision Determination of Eligible Living in a Dormitory
b. Criteria and Weight:

In this study we determined 4 criteria that we wrote down with $\mathrm{C} 1$ to $\mathrm{C} 4$. Explanation of the four criteria can be seen in table 1 . We write the weights and criteria specified in table 1 on the system that we have created (Figure 2).

Table 1. Criteria and weights

\begin{tabular}{ccc}
\hline Criteria & Description & Weight \\
\hline C1 & Routine Absent & 0.375 \\
C2 & Non Routine & 0.2 \\
& Absence & \\
C3 & Violation & 0.275 \\
C4 & Note & 0.15 \\
\hline
\end{tabular}

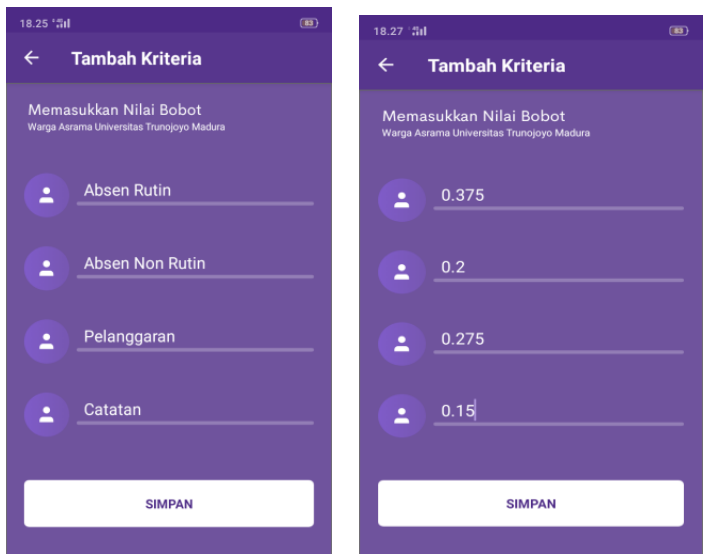

Fig 2. Write the weights on the criteria

In entering the score into the system, we provide a range of the four criteria to make it easier to calculate (Figure 1). So the user will enter a score for each resident based on the range of scores in the four criteria. In Table 2 for the range of routine absences if one of the residents of the dormitory does not do more than ten times the routine absence then will get a score of 1 with a red card statement. And if one of the residents is less than equal to seven times not doing routine absences then get a score of three with a green card statement..

Table 2. Range of Routine Absence values

\begin{tabular}{ccc}
\hline Range of Value & Score & Description \\
\hline$>10$ & 1 & Red Card \\
$>=8$ & 2 & Yellow card \\
$<=7$ & 3 & Green Card \\
\hline
\end{tabular}

In table 2 describes the scoring for nonroutine absence values. The range of values in this criterion is if one resident does more than two non-routine absences then the score is one. Conversely, if always perform routine absent zero absent or non-routine then get the value of the score is three. Table 3 explains the grading of violation value criteria and records. 
In both of these criteria if one of the people do not infringe and does not have a record of it will get a green card with the maximum score is three. Meanwhile, if the residents do a lot of offense and have a record of it will get a red card with a score value is one.

Table 3. Range of Non Routine Absence values

\begin{tabular}{ccc}
\hline Range of Value & Score & Description \\
\hline$>2$ & 1 & Red Card \\
$>=1$ & 2 & Yellow card \\
0 & 3 & Green Card \\
\hline
\end{tabular}

Table 4. Range of Abuse and Note values

\begin{tabular}{cc}
\hline Score & Description \\
\hline 1 & Red Card \\
2 & Yellow card \\
3 & Green Card \\
\hline
\end{tabular}

\section{RESULT AND DISCUSSION}

\section{Application Development}

In the decision making process to make it easier for administrators to determine boarding residents who deserve to live, we built a decision support system on mobile applications. In this application we provide security by providing a login page that functions that the system can only be used for authorized users. Followed by a starting page with 4 main features (student data, criteria, calculation results, and dormitory regulations) and 1 additional feature (about the developer)).

Figure $3-5$ is a display of the mobile application that has been built by the author. Figure 2 shows the user must log in first by entering a username and password in order to access the application. users can add occupant data by filling in the existing fields and there are also hostel rules (Figure 3). while in figure 4 , users are presented with a data display of students who are residents of the dormitory.

The criteria feature is a feature that provides input to the criteria weights used as calculations. The calculation results feature contains a calculation table obtained by applying the TOPSIS method. Whereas the dormitory regulations feature displays a list of the regulations that are in the dormitory.

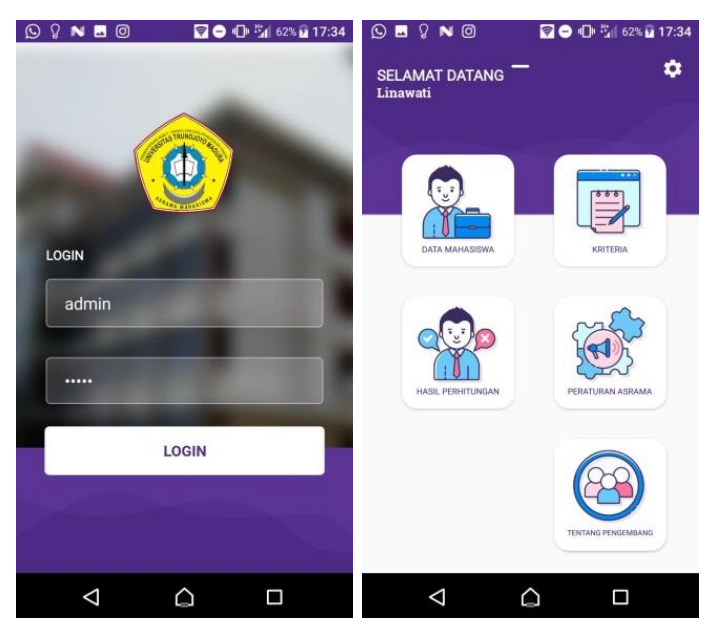

Fig 3. Log in and homepage

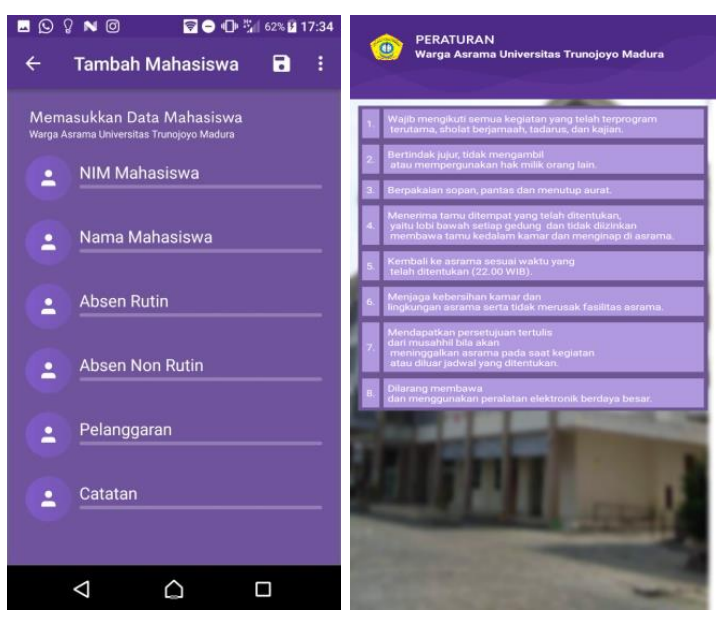

Fig 4. Add residents along with the scores of each dormitory's criteria and regulations

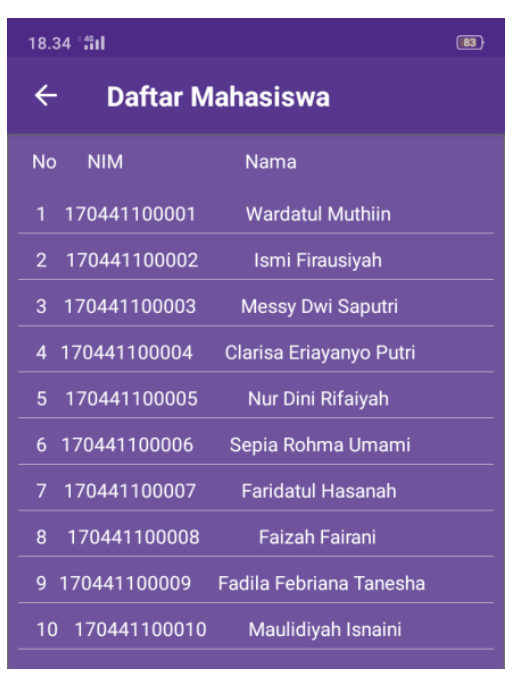

Fig 5. Sample list of boarding residents 


\section{Analysis of the TOPSIS Method calculation}

a. Sampling data were taken from 10 residents of the total number of dormitory residents as many as 216 boarding residents who currently live.

Based on the ten data we assume with alternatives A1 through A10. When entering the list of citizens the scores of the four criteria have been written down which can also be seen in table 5 . We assume alternatives $(\mathrm{Al})$, routine absences ( $\mathrm{RA})$, nonroutine absences (NR), violations (Vi), and notes $(\mathrm{Nt})$.

Table 5. Alternative score criteria values

\begin{tabular}{ccccc}
\hline $\mathbf{A l}$ & $\mathbf{R A}$ & $\mathbf{N R}$ & $\mathbf{V i}$ & $\mathbf{N t}$ \\
\hline $\mathbf{A 1}$ & 3 & 2 & 2,5 & 2,5 \\
$\mathbf{A 2}$ & 3 & 3 & 2,5 & 2,5 \\
$\mathbf{A 3}$ & 3 & 2 & 3 & 3 \\
$\mathbf{A 4}$ & 3 & 3 & 3 & 3 \\
$\mathbf{A 5}$ & 3 & 3 & 2,5 & 2,5 \\
$\mathbf{A 6}$ & 3 & 2 & 3 & 3 \\
$\mathbf{A 7}$ & 1 & 3 & 3 & 3 \\
$\mathbf{A 8}$ & 3 & 3 & 2,5 & 2,5 \\
$\mathbf{A 9}$ & 3 & 3 & 3 & 3 \\
$\mathbf{A 1 0}$ & 3 & 3 & 3 & 3 \\
\hline
\end{tabular}

b. After knowing the problems, criteria, weights and alternatives, the next step is to calculate normalization. To get the normalization value, first look for the $\mathrm{X}$ value. The $X$ value can be seen in table 6 and Table 7 is the normalization value.

Table 6. $\mathrm{X}$ value

\begin{tabular}{|l|l|l|}
\hline X Value & $\mathrm{RA}$ & 42.6380112 \\
\cline { 2 - 3 } & $\mathrm{NR}$ & 43.89760814 \\
\cline { 2 - 3 } & $\mathrm{Vi}$ & 40.7553677 \\
\cline { 2 - 3 } & $\mathrm{Nt}$ & 40.755 \\
\hline
\end{tabular}

Based on normalization values, weighting normalization calculation is done by applying equation 2. The results of weighting normalization can be seen in table 8 while positive ideal values and negative ideal values can be seen in table 9.
Tabel 7. Normalization

\begin{tabular}{ccccc}
\hline $\mathbf{A l}$ & $\mathbf{R A}$ & $\mathbf{N R}$ & $\mathbf{V i}$ & $\mathbf{N t}$ \\
\hline $\mathbf{A 1}$ & 0,3312 & 0,2309 & 0,2812 & 0,2812 \\
& 94578 & 40108 & 71975 & 7 \\
$\mathbf{A 2}$ & 0,3312 & 0,3464 & 0,2812 & 0,2812 \\
& 94578 & 10162 & 71975 & 7 \\
$\mathbf{A 3}$ & 0,3312 & 0,2309 & 0,3375 & 0,3375 \\
& 94578 & 40108 & 2637 & 3 \\
$\mathbf{A 4}$ & 0,3312 & 0,3464 & 0,3375 & 0,3375 \\
& 94578 & 10162 & 2637 & 3 \\
$\mathbf{A 5}$ & 0,3312 & 0,3464 & 0,2812 & 0,2812 \\
& 94578 & 10162 & 71975 & 7 \\
$\mathbf{A 6}$ & 0,3312 & 0,2309 & 0,3375 & 0,3375 \\
& 94578 & 40108 & 2637 & 3 \\
$\mathbf{A 7}$ & 0,1104 & 0,3464 & 0,3375 & 0,3375 \\
& 31526 & 10162 & 2637 & 3 \\
$\mathbf{A 8}$ & 0,3312 & 0,3464 & 0,2812 & 0,2812 \\
& 94578 & 10162 & 71975 & 7 \\
A9 & 0,3312 & 0,3464 & 0,3375 & 0,3375 \\
& 94578 & 10162 & 2637 & 3 \\
A10 & 0,3312 & 0,3464 & 0,3375 & 0,3375 \\
& 94578 & 10162 & 2637 & 3 \\
\hline
\end{tabular}

Table 8. Weighting Normalization

\begin{tabular}{ccccc}
\hline Al & RA & NR & Vi & Nt \\
\hline A1 & 0,1242 & 0,0461 & 0,0773 & 0,0421 \\
& 35467 & 88022 & 49793 & 9 \\
$\mathbf{A 2}$ & 0,1242 & 0,0692 & 0,0773 & 0,0421 \\
& 35467 & 82032 & 49793 & 9 \\
A3 & 0,1242 & 0,0461 & 0,0928 & 0,0506 \\
& 35467 & 88022 & 19752 & 3 \\
A4 & 0,1242 & 0,0692 & 0,0928 & 0,0506 \\
& 35467 & 82032 & 19752 & 3 \\
A5 & 0,1242 & 0,0692 & 0,0773 & 0,0421 \\
& 35467 & 82032 & 49793 & 9 \\
A6 & 0,1242 & 0,0461 & 0,0928 & 0,0506 \\
& 35467 & 88022 & 19752 & 3 \\
A7 & 0,0414 & 0,0692 & 0,0928 & 0,0506 \\
& 11822 & 82032 & 19752 & 3 \\
A8 & 0,1242 & 0,0692 & 0,0773 & 0,0421 \\
& 35467 & 82032 & 49793 & 9 \\
A9 & 0,1242 & 0,0692 & 0,0928 & 0,0506 \\
& 35467 & 82032 & 19752 & 3 \\
A10 & 0,1242 & 0,0692 & 0,0928 & 0,0506 \\
& 35467 & 82032 & 19752 & 3 \\
\hline
\end{tabular}


Table 9. Determine the positive and negative ideal values

\begin{tabular}{ccccc}
\hline $\begin{array}{c}\text { ideal } \\
\text { values }\end{array}$ & RA & NR & Vi & Nt \\
\hline Positiv & 0,124235 & 0,0692 & 0,0928 & 0,05 \\
e & 467 & 82032 & 19752 & 063 \\
Negati & 0,041411 & 0,0461 & 0,0773 & 0,04 \\
ve & 822 & 88022 & 49793 & 219 \\
\hline
\end{tabular}

c. The next stage is looking for the distance between the weighted values of each alternative ideal values positive and negative. Calculation of the distance in the TOPSIS method by applying the calculation of the euclidean distance. The concept of calculating euclidean distances is to compare 2 values or points in euclidean space.

Table 10. Calculation of distances for positive ideal and negative ideal

\begin{tabular}{ccc}
\hline Alternatif & Positif & Negatif \\
\hline A1 & 0,029049191 & 0,082823645 \\
A2 & 0,017621639 & 0,085983076 \\
A3 & 0,023094011 & 0,084677496 \\
A4 & 0 & 0,08777022 \\
A5 & 0,017621639 & 0,085983076 \\
A6 & 0,023094011 & 0,084677496 \\
A7 & 0,082823645 & 0,029049191 \\
A8 & 0,017621639 & 0,085983076 \\
A9 & 0 & 0,08777022 \\
A10 & 0 & 0,08777022 \\
\hline
\end{tabular}

Based on table 10, it can be seen the value of the distance between two ideals (positive ideal and negative ideal). If the value is close to 0 or even 0 , the value is at the ideal. Some alternatives have a value of 0 on a positive ideal, namely A4, A9 and A10, so the three alternatives can be said to have a positive ideal. For more details, we can see in table 11 and figure 6 which is the final value of the TOPSIS calculation.
Table 11. Value or the final value of the TOPSIS method calculation.

\begin{tabular}{|c|c|c|c|}
\hline Al & Value & Rank & Color \\
\hline A1 & $\begin{array}{c}0,74033740 \\
5\end{array}$ & 183 & yellow \\
\hline $\mathbf{A} 2$ & $\begin{array}{c}0,82991470 \\
3\end{array}$ & 120 & green \\
\hline A3 & $\begin{array}{c}0,78571320 \\
4\end{array}$ & 180 & green \\
\hline A4 & 1 & 1 & green \\
\hline A5 & $\begin{array}{c}0,82991470 \\
3\end{array}$ & 119 & green \\
\hline A6 & $\begin{array}{c}0,78571320 \\
4\end{array}$ & 178 & green \\
\hline $\mathbf{A} 7$ & $\begin{array}{c}0,25966259 \\
5\end{array}$ & 201 & red \\
\hline A8 & $\begin{array}{c}0,82991470 \\
3\end{array}$ & 119 & green \\
\hline A9 & 1 & 1 & green \\
\hline A10 & 1 & 1 & green \\
\hline
\end{tabular}

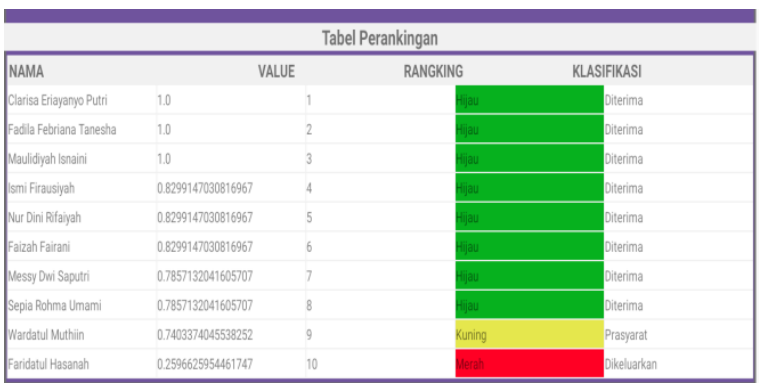

Fig 6. Ranking Table with 10 sample data

Accuracy testing is used to determine the ability of the system to make decisions, whether the results are accurate or not. Here is a sample of 10 data from a total of 216 data can be seen in table 12 .

The actual results were obtained by calculating the TOPIS method manually using the help of Microsoft Excel software. while the prediction result is the calculation result of the TOPSIS method which has been implemented into the system. Comparison of accuracy testing is used to determine the ability of the system to make decisions. 
Tabel 12. Comparison of results

\begin{tabular}{|c|c|c|c|c|c|}
\hline Al & Value & Rank & Prediction & Actual & Results \\
\hline A1 & $\begin{array}{c}0,74 \\
0337\end{array}$ & 183 & yellow & yellow & $\sqrt{ }$ \\
\hline A2 & $\begin{array}{c}0,82 \\
9915\end{array}$ & 120 & green & yellow & $x$ \\
\hline $\mathbf{A 3}$ & $\begin{array}{c}0,78 \\
5713\end{array}$ & 180 & green & green & $\sqrt{ }$ \\
\hline A4 & 1 & 1 & green & green & $\sqrt{ }$ \\
\hline A5 & $\begin{array}{c}0,82 \\
9915\end{array}$ & 119 & green & green & $\sqrt{ }$ \\
\hline A6 & $\begin{array}{c}0,78 \\
5713\end{array}$ & 178 & green & green & $\sqrt{ }$ \\
\hline A7 & $\begin{array}{c}0,25 \\
9663\end{array}$ & 201 & red & red & $\sqrt{ }$ \\
\hline A8 & $\begin{array}{c}0,82 \\
9915\end{array}$ & 119 & green & green & $\sqrt{ }$ \\
\hline A9 & 1 & 1 & green & green & $\sqrt{ }$ \\
\hline A10 & 1 & 1 & green & green & $\sqrt{ }$ \\
\hline
\end{tabular}

In conducting test calculations using the confusion matrix method. In this method there are four terms namely true positive (TP), false negative (FN), true negative (TN), and false positive (FP) for 2 classes namely positive and negative [19]. If the positive and correct sample is decided as positive it is counted as TP; and if the sample is decided as negative then FN is considered. If the sample is negative and is decided negative then it is considered TN; if classified as positive, then it is calculated as FP. From Table 12, we get the results from the system predictions and actual results. Based on the table, the accuracy of the prediction is calculated by determining the class prediction (Table 13). Accuracy results of $90 \%$ (Table 14) are obtained by adding up

\section{REFERENCES}

[1] Ramesh Sharda, Steve H. Barr, and James C. McDonnell, "Decision Support System Effectiveness: A Review and an Empirical Test," Management Science, vol. 34, no. 2, pp. 139-159, 1988.

[2] A. F. Lukasheh, R. L. Droste, and M. A. Warith, "Review of Expert System (ES), Geographic Information System (GIS), Decision Support System the results of correct decisions and wrong decision results that are considered wrong divided by the overall results of the decision.

Table 13. Accumulation of class predictions

\begin{tabular}{lcll}
\hline TP & FN & TN & FP \\
\hline 9 & 0 & 0 & 1 \\
\hline Table 14. Accuracy & \\
\hline \multirow{2}{*}{ ACCURACY } & $\begin{array}{r}(\mathrm{TP}+\mathrm{TN}) / \\
(\mathrm{TP}+\mathrm{FP}+\mathrm{FN}+\mathrm{TN})\end{array}$ \\
\cline { 2 - 3 } & \multicolumn{2}{|c|}{0.9} \\
\hline
\end{tabular}

\section{CONCLUSION}

Based on the results of the study by applying the TOPSIS method for the determination of boarders who are eligible to stay, it can be concluded that the making of this decision support system application is able to provide the best decision solution and provide accurate results with the criteria determined by the board administrator. The calculation is done using 10 data from 216 total boarding residents who currently live. The application will display the final calculation data sorted by ranking the level of eligibility of residence. The ranking makes it easy for administrators to see the data and also decides which residents will remain or must be removed from the dormitory. The green color indicates that the residents are in a safe position, the yellow color indicates that the residents are in a vulnerable condition and the red color indicates the residents are expelled
(DSS), and their applications in landfill design and management," Waste Management \& Research, vol. 19, pp. 177-185, 2001.

[3] E. K. Zavadskas, A. Mardani, Z. Turskis, A. Jusoh, and a. K. M. Nor, "Development of TOPSIS Method to Solve Complicated Decision-Making Problems: An Overview on Developments from 2000 to 2015," 
International Journal of Information Technology \& Decision Making, vol. 15, pp. 645-682, 2016.

[4] J.M. Sánchez-Lozano, M.S. GarcíaCascales, and M. T. Lamata, "Comparative TOPSIS-ELECTRE TRI methods for optimal sites for photovoltaic solar farms. Case study in Spain," Journal of Cleaner Production, 2016.

[5] P. Biswas, S. Pramanik, and B. C. Giri, "TOPSIS method for multiattribute group decision-making under single-valued neutrosophic environment," Neural Comput \& Applic, 2015.

[6] F. E. Allakia, e. C. , and A. Vallièresa, "A modified TOPSIS (Technique for Order of Preference by Similarity to Ideal Solution) applied to choosing appropriate selection methods in ongoing surveillance for Avian Influenza in Canada," Preventive Veterinary Medicine, vol. 165, pp. 3643, 2019.

[7] R. E. Setyani and R. Saputra, "Floodprone Areas Mapping at Semarang City by Using Simple Additive Weighting Method," Procedia - Social and Behavioral Sciences, vol. 227, pp. 378-386, 2016.

[8] Y.-J. Wang, "Interval-valued fuzzy multi-criteria decision-making based on simple additive weighting and relative preference relation," Information Sciences, vol. 503, pp. 319-335, 2019.

[9] M. Rajasekhar, G. Sudarsana Raju, Y. Sreenivasulu, and R. Siddi Raju, "Delineation of groundwater potential zones in semi-arid region of Jilledubanderu river basin, Anantapur District, Andhra Pradesh, India using fuzzy logic, AHP and integrated fuzzy-AHP approaches," HydroResearch, vol. 2, pp. 97-108, 2019.

[10] A. Khashei-Siuki, A. keshavarz, and H. Sharifan, "Comparison of AHP and FAHP methods in determining suitable areas for drinking water harvesting in Birjand aquifer. Iran," Groundwater for Sustainable Development, vol. 10, 2020.

[11] A. L. Achu, J. Thomas, and R. Reghunath, "Multi-criteria decision analysis for delineation of groundwater potential zones in a tropical river basin using remote sensing, GIS and analytical hierarchy process (AHP)," Groundwater for Sustainable Development, vol. 10, p. 100365, 2020..

[12] S. Hasnain, M. K. Ali, J. Akhter, B. Ahmed, and N. Abbas, "Selection of an industrial boiler for a soda-ash production plant using analytical hierarchy process and TOPSIS approaches," Case Studies in Thermal Engineering, vol. 19, 2020.

[13] H. Shakouri G, M. Nabaee, and S. Aliakbarisani, "A quantitative discussion on the assessment of power supply technologies: DEA (data envelopment analysis) and SAW (simple additive weighting) as complementary methods for the "Grammar"," Energy, vol. 64, pp. 640-647, 2014.

[14] F. Dweiri, S. Kumar, S. A. Khan, and V. Jain, "Designing an integrated AHP based decision support system for supplier selection in automotive industry," Expert Systems With Applications, vol. 62, no. 273-283, 2016.

[15] R. A. Zulfikar and A. A. Supianto, "Rancang Bangun Aplikasi Antrian Poliklinik Berbasis Mobile," Jurnal Teknologi Informasi dan Ilmu Komputer, vol. 5, no. 3, p. 361, 2018.

[16] D. Arnott and G. Pervan, "A Critical Analysis of Decision Support Systems Research Revisited: The Rise of Design Science," Enacting Research Methods in Information Systems, pp. 43-103, 2016.

[17] D. J. Powera and R. Shardab, "Modeldriven decision support systems: Concepts and research directions," Decision Support Systems, vol. 43, pp. 1044-1061, 2007. 
144 Jurnal Ilmiah KURSOR Vol. 10, No. 3, Juli 2020, hal 135 - 144

[18] P. Chen, "Effects of normalization on the entropy-based TOPSIS method," Expert Systems With Applications, vol. 136, pp. 33-41, 2019.
[19] A. Tharwat, "Classification assessment methods," Applied Computing and Informatics, 2018. 